\title{
HUMOR DA CHARGE POLÍTICA NO JORNAL
}

\section{Sátira, comentário e banalização dos fatos cotidianos e da política nacional fazem parte da prática do chargista}

Jornais sempre encontraram um jeito de vender mais, independentemente do produto principal que apregoam, a notícia. Como o vendedor de cachorro quente que compra o pão e a salsicha na mesma padaria que seus concorrentes e alardeia as vantagens do seu molho, os jornais vivem muito mais do "toque pessoal" que dão a um recheio mais ou menos comum a todos. As Agências Internacionais, por exemplo, apresentam quase que as mesmas notícias, com mais ou menos os mesmos enfoques. Raros são os furos, raras as pautas totalmente originais em tempos onde se procura construir uma estabilidade institucional sobre os pilares de uma estabilidade monetária que ainda não provou ter fôlego de fundista.

O que diferencia um jornal do outro, então? Muitas vezes é a enciclopédia em fascículos encartada nas edições dominicais. Outras vezes é o time de colunistas e articulistas de opinião que cada um apresenta na vitrina. Com a crescente "objetivação" do noticiário em geral e uma pretensa imparcialidade das pautas, revalorizou-se no país o colunismo opinativo. Estes adereços acabam sendo o diferencial de cada veículo. Por serem exatamente o "toque pessoal", eles só têm função se funcionarem como antenas do jornal, abridores de picadas, aventureiros por "mares nunca dantes navegados" dentro das páginas diárias. De nada vale um José Simão ou um Élio Gaspari, por exemplo, se, cada um à sua maneira, não levar o leitor a pontos mais distantes que o noticiário diário, se não forem mais ousados que o próprio corpo do jornal.

Com o desenvolvimento acelerado da cobertura televisiva, o jornal perdeu sua função de trazer ao leitor as "últimas notícias".

A CNN cobre em velocidade instantânea a mais obscura guerrilha no ponto mais distante do planeta. O papel reflexivo do jornal, de contar o que está por trás do fato, quais suas causas e porquês, acaba tendo muito mais importância do que suas características informativas. Informar acaba sendo uma mera obrigação.

\section{O AUTOR}

\section{Gilberto Maringoni}

Chargista do jornal o Estado de S. Paulo, editor de arte da revista Atenção, quadrinhista e arquiteto formado pela Faculdade de Arquitetura e Urbanismo da USP. 
É claro que a própria informação não é neutra. Um redator ou um editor, quando escreve uma matéria, já toma diversas opções subjetivas sobre que aspecto do fato realçar, que ponto reforçar no título e em que lugar da página colocar a matéria. Estas opções induzem a uma determinada compreensão do fato narrado. Um massacre de trabalhadores sem-terra pode, por exemplo, ser relatado como uma reação bárbara de uma quadrilha de fazendeiros a um dos mais graves problemas sociais do país ou como uma legítima defesa da propriedade privada ameaçada por um bando de desordeiros que quer subverter a paz social.

A charge é parte desses "penduricalhos" que o jornal apresenta como material de opinião. Não é à toa que ela sempre está colocada na página de editoriais, a página nobre. A charge acaba sendo uma espécie de "editorial gráfico", como dizia o Fortuna, um dos grandes profissionais da área que este país já teve.

Com uma diferença, lembrava ele: enquanto num artigo o autor pode, após um contundente ataque, emendar um "mas-contudo-todavia", na charge estes malabarismos de estilo não são muito per-

\section{HISTORIA SEM FIM}

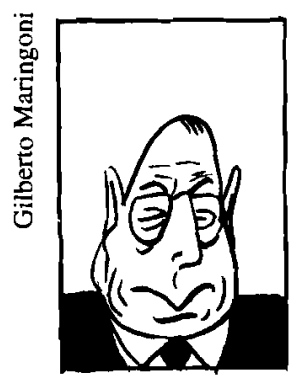

FIGUEIREDO FOI SUCEDIDO POR...

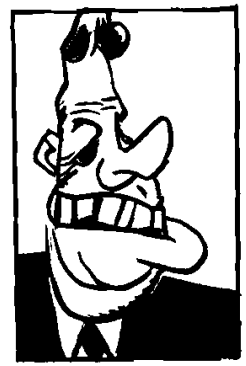

..FERNANDO HENRIGUE QUE QUER SER SUCEDIDO POR...

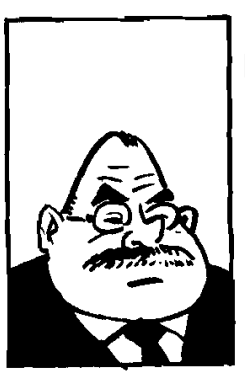

... SARNEY, QUE FOI SUCEDIDO

POR ...

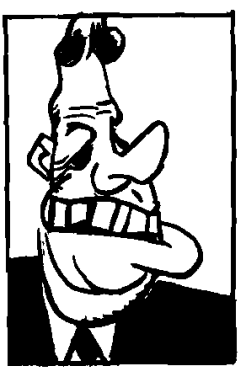

...FERNANDO HENRIQUE QUE GUER SER SUCEDIDO FOR...

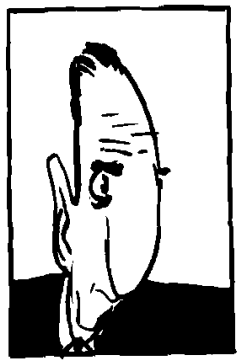

... COLLOR QUE FOI SUCEDIDO POR...

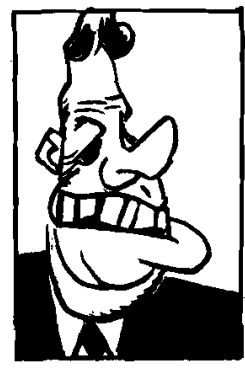

FERNANDO HENRIOUE QUE QUER SER SUCEDIDO POR...

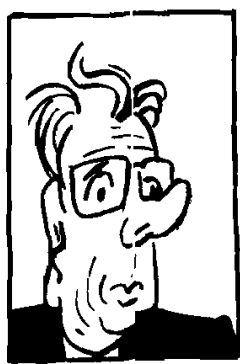

..ITAMAR, QUE FOl SUCLDDIDO POR ...

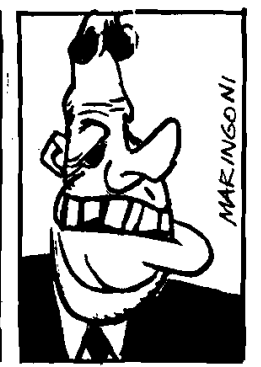

...FERNANDO HENRIQUE QUE QUER ETC., ETC., ETC... mitidos. A charge palavra que vem do francês carga, de "carga de cavalaria" - não permite muitas acrobacias de estilo e conteúdo. A charge ou é contra ou é a favor. É porrada ou não. Essa unidimensionalidade da charge - e por extensão da caricatura - levou Paulo Francis, no tempo em que era jornalista, em 1964 , a afirmar que ela se constituía numa forma menor da expressão do humor. Verdade ou não, o país conheceu momentos memoráveis da charge política, onde por vezes ela atingiu o status de grande meio de expressão. 
Notáveis foram os períodos do Segundo Império - na época em que o ítalo-brasileiro Ângelo Agostini "detonava" a aristocracia, o clero e a politicalha de então - e aquele que coincidiu com o golpe militar, período em que surgiu um time de profissionais de altíssimo nível, como Ziraldo, Jaguar, Henfil etc.

\section{ILUSTRAÇÃO NÃO É CHARGE}

No entanto, como expressão gráfica do arreglo e da característica típica da vida política brasileira de se evitar o conflito, surgiu, com o fim da ditadura, um tipo de charge semelhante à feijoada: tem traços de charge, tem personagens de charge, está editada no lugar da charge, mas não é charge; é ilustração. A charge-feijoada surgiu basicamente na esteira dos imitadores de um chargista genial, Chico Caruso. Dono de um traço invulgar e de uma graça e agressividade ímpares em seus trabalhos - basta que se confiram seus desenhos da época do impeachment de Collor. Chico involuntariamente gerou uma plêiade de seguidores que estão a quilômetros de seu talento. Imitando apenas seu desenho, eles se esmeram em caprichadas artesfinais, desenhos sem palavras e um humor de salto alto que não ataca ninguém e tenta fazer o leitor crer que a vida política nacional se resume a um convescote entre FHCs, ACMs, Malufs e quejandos.

O chargista, como qualquer jornalista, deve antes de tudo saber para qual veículo está trabalhando e qual a orientação editorial do órgão, sem, no entanto, perder suas características artísticas e de opinião. Sempre é melhor quando o desenhista pode se pautar - isto é, escolher o assunto que deseja tratar - e tem um bom entrosamento com o editor sobre qual a maneira de abordar este ou aquele assunto. Interesses editoriais existem até em jornais de Centros Acadêmicos. Mas ousadia é fundamental. Quando se faz uma charge é importante estar informado sobre o assunto a ser tratado e ter opinião sobre ele. Charges sobre elementos do mundo político, que sabidamente estão rapinando o país, devem ser feitas pisando-se em ovos. De preferência nos deles.

Bom senso também não faz mal a ninguém. Coisa que alguns chamam de auto-censura. De nada adianta, como uma vez lembrou o cartunista Laerte, alguém passar na rua e jogar um tijolo na testa do guarda. A auto-censura age nestas horas e faz você ver que, em seguida, trinta guardas virão atrás de você não exatamente para lhe fazer cafuné. Na charge acontece de forma semelhante. De nada adianta ser falsamente radical, se a sua porrada não criar cumplicidade com o leitor. 
Para se fazer humor é preciso haver cumplicidade com o público. Ninguém ri da piada que você conta, se não existe um código prévio entre você e seus ouvintes. Muitas vezes, este código está baseado no mais repugnante dos preconceitos, mas ele - o vínculo - deve existir.

Há opiniões médias na sociedade sobre portugueses, judeus, negros, homossexuais, japoneses e diversos outros grupos, carregadas de preconceitos. Não vamos entrar aqui nos méritos e porquês disso. Mas estas opiniões é que garantem o sucesso das eternas piadas sobre cada um destes personagens. Ninguém conta piadas sobre $o$ japonês pão-duro ou o alemão burro. Não é isto que reza o código que as pessoas têm sobre cada uma dessas nacionalidades. Assim acontece na charge de jornal. Ninguém faz um desenho comemorando a morte de Ayrton Senna, por exemplo. Isso agride o leitor, vale dizer, o código de comunicação entre o profissional e o público, porque o sentimento geral é de consternação e choque pela morte de um ídolo.

\section{UM CÓDIGO EM COMUM COM O LEITOR}

A existência de um código permite que se associem acontecimentos que à primeira vista não possuem ligação alguma. Vou dar um exemplo. Em setembro do ano passado, o Banco Central anunciou a intervenção no Banco Econômico. A medida provocou uma disputa acalorada entre os membros da base de sustentação do governo. ACM veio a público xingar a diretoria do Banco Central de ser constituída por "marginais"; Gustavo Loyola retrucou com um palavreado abaixo da cintura e o presidente insinuou que seus detratores tinham a "cueca suja". Enfim, uma verborragia que provocaria escândalo em banheiro de botequim. Na mesma época, um violento quebra-quebra entre torcidas organizadas no Pacaembu, que resultou em um morto e vários feridos, gerou em todo o país uma indignação maior que o escândalo dos bancos. Decidi juntar as duas coisas numa charge que retratava a cena da briga entre as torcidas, onde os personagens nas arquibancadas berravam exatamente as mesmas frases faladas por FHC, ACM et caterva. Nesta situação particular, os fatos estavam na cabeça de todos e podiam ser ligados com um componente humorístico muito forte. 


\section{Este código} cultural e emocional tem características universais e possui também particularidades locais. Em qualquer lugar do mundo pode-se rir num filme de Chaplin quando Carlitos escorrega numa casca de banana. Mas nem todo mundo vai achar graça no Amigo da Onça, que retratava um tipo bem brasileiro. Um estudioso francês, Maurice Daninos, disse certa vez que "no mundo todo as pessoas podem rir das mesmas coisas, mas nem sempre pelos mesmos motivos". Uma piada de português só tem efeito no Brasil. Se você a contar na França, não será compreendido e em Portugal, linchado. No entanto, a mesma piada pode ser contada na Catalunha, por exemplo, se o personagem for um habitante de cidade de Fete. A fama do pão-duro no Brasil é debitada ao judeu; na Inglaterra, ao escocês.

A charge envolve mais um componente neste código com 0 público: o tempo. Peguemos o exemplo da casca de banana de Carlitos. A cena é universal e atemporal. Vista hoje, daqui a dez ou vinte anos, ou há vinte, quarenta anos atrás, a graça continua. No entanto, se trocarmos a personagem por, digamos, o Antônio Carlos Magalhães, a piada fica datada. Ela só tem efeito porque se conhece a importância que o ACM tem na vida brasileira hoje. Daqui a algum tempo, espero, ele não terá relevância alguma e a piada perderá totalmente o sentido. Por ser datada, a charge é tão perene quanto um pão amanhecido. Ela pode ficar como registro de uma época (é possível se analisar a República Velha pelos desenhos de J. Carlos, Kalixto etc.) mas dificilmente a graça permanece. A não ser, é claro, que se tenha uma explicação clara sobre os fatos do período. Mas, como todos sabem, explicação mata qualquer piada. 
Alguns cartunistas conseguem com seu trabalho captar mais o espírito de uma época do que se limitar ao registro do fato do dia. Neste caso, não temos mais a charge política, mas a crítica de costumes e ela adquire uma característica mais duradoura. Exemplos típicos são o já citado Amigo da Onça, de Péricles, o Fradim, do Henfil, a Rê Bordosa, do Angeli.

Mas afinal, a charge vende mais jornal? A pergunta não é lá muito pertinente, porque poucas coisas isoladamente vendem mais jornal. Mas o fato de hoje praticamente todos os grandes jornais brasileiros publicarem charges - alguns até na capa - indica uma tendência de se colocar o desenho de opinião com um peso editorial

-DARIA PRA DEFENDER A MINHA TRADICÁO, A MiNHA FAMILIA E A MINHA

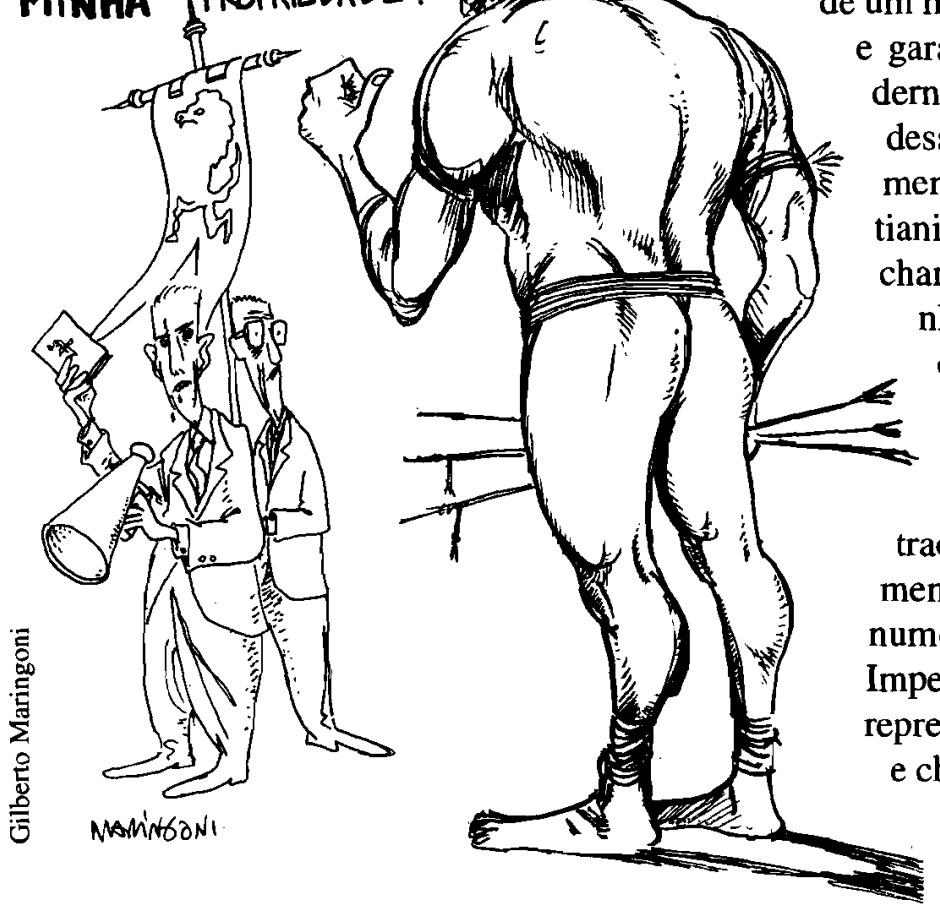

Herman Lima, no seu clássico História da Caricatura no Brasil, relata a descoberta numa das ruas do monte Palatino, em Roma, de um muro com uma série de "riscos e garatujas", como se fossem modernas pichações e grafites. Um desses rabiscos, feito provavelmente por um adversário do cristianismo, representa um cristão chamado Alexamenos. No desenho, Cristo é representado na cruz com a cabeça de um asno, ladeado pela figura de outro homem em atitude reverencial. Acima da ilustração, lê-se a inscrição "Alexamenos adora seu Deus". Os monumentos e palácios da Roma mperial foram construídos para epresentar o poderio dos Césares e chegaram até nós como um testemunho perene do prodígio humano. $O$ rabisco numa parede contra o tal Alexamenos, sobre quem a história não deixou outro registro, representa a perenização da molecagem, realizada num momento extremamente particular contra um personagem também muito definido. Provavelmente, a relação que a charge guarde com o jornal seja essa: a de um rabisco no pé de um monumento, que com alguma sorte será engraçado pelo menos até a semana que vem. 
Resumo: O chargista Maringoni trata das características da charge política nas páginas dos grandes jornais. Comenta o humor e a frágil perenidade deste tipo de "editorial gráfico" do cotidiano nacional. Relaciona os principais chargistas que passaram pela imprensa brasileira, desde Ângelo Agostini até Chico Caruso.

Palavras-chave: Charge política, jornais, objetivação, humor, editorial.

Abstract: The caricaturist Maringoni talks about the characteristics of the political caricature on the pages of important newspapers. He comments on the humor and the fragile perenity of this kind of ô graphic editorialö on the national daily newspapers. He lists the most important caricaturists who worked for the Brazilian press, from Angelo Agostini to Chico Caruso.

Key-words: caricature, newspapers, humor, editorial.

ACABOU A FESTA

\section{AUMENTARAM OS CARROS IMFORTADOS...}
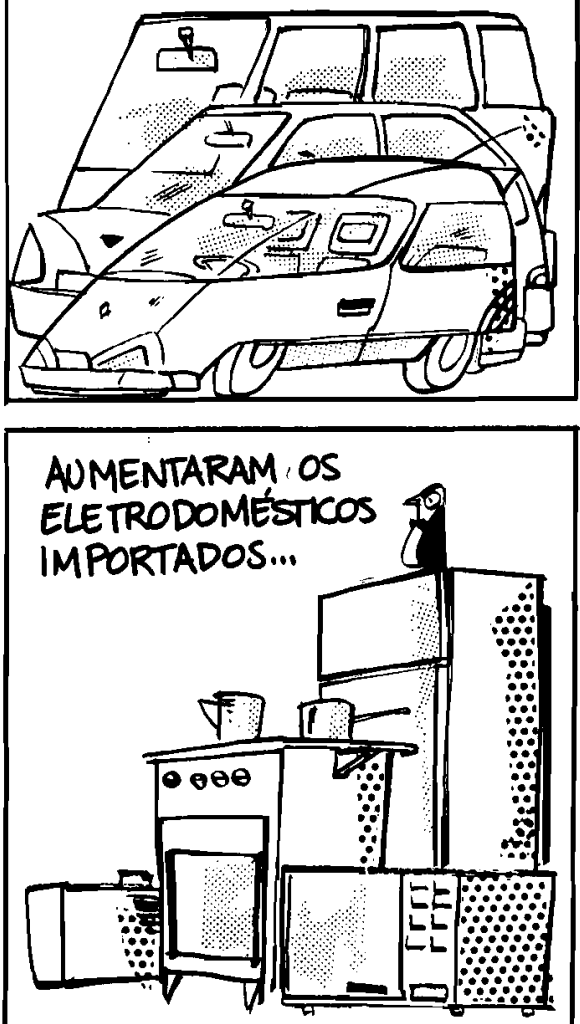

AUMENTARAM OS ELETRÓNICOS IMPORTADOS.".
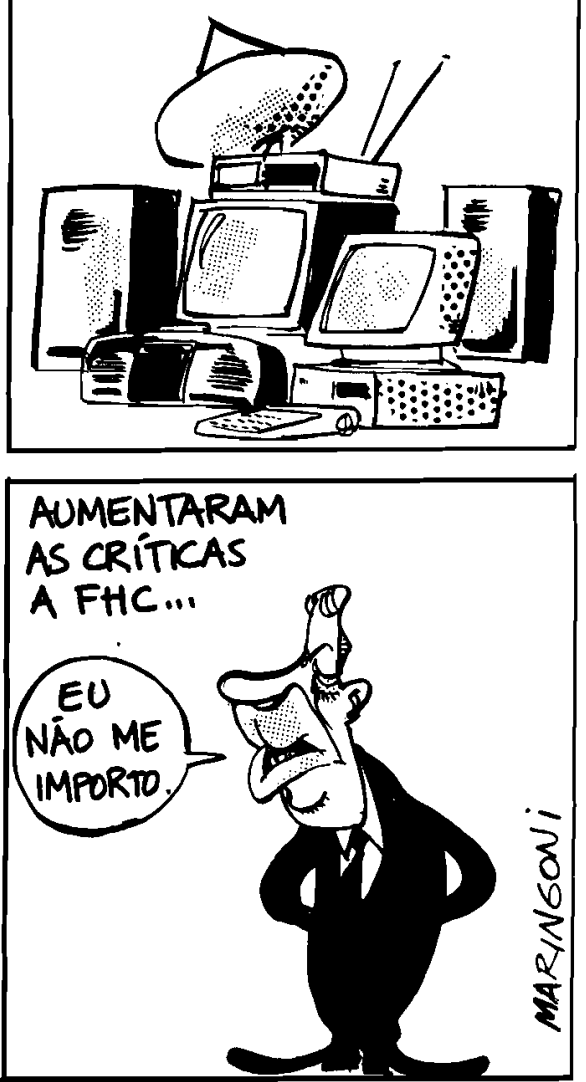